\title{
A STUDY OF HUMAN ERROR FACTORS ON MARITIME ACCIDENT RATES IN MARITIME INDUSTRY
}

\author{
Ismila Che Ishak*, Mohamad Fitri Azlan, Shaiful Bakri Ismail, \\ and Norhayati Mohd Zainee
}

Universiti Kuala Lumpur Malaysian Institute of Marine Engineering Technology, Jalan Pantai Remis, Lumut, Perak, Malaysia

*Corresponding author: ismila@unikl.edu.my

Published online: 25 October 2019

To cite this article: Che Ishak, I., Azlan, M.F., Ismail, S.B., and Mohd Zainee, N. (2019). A study of human error factors on maritime accident rates in maritime industry. Asian Academy of Management Journal, 24(Supp. 2), 17-32. https://doi.org/10.21315/ aamj2019.24.s2.2

To link to this article: https://doi.org/10.21315/aamj2019.24.s2.2

\begin{abstract}
Human error is the result of human actions. It is an actual action in daily life that could cause an accident and an intentional infringement. The purpose of this research is to analyse three factors of human error, namely fatigue, communication, and lack of technical knowledge as the major contributors to the occurrence of accidents. In addition, it seeks to determine the relationship between these factors and accidents in the maritime industry. A number of 60 respondents from an oil and gas company, and a government agency located in Lumut, Perak, Malaysia participated in this research. The results show a strong positive relationship between the human factors which include fatigue, communication, and lack of knowledge towards the maritime accident rates. Among the three, the lack of technical knowledge is the highest contributing factor which could seriously cause accidents in the maritime industry.
\end{abstract}

Keywords: fatigue, communication, technical knowledge, marine environment, marine accidents

(C) Asian Academy of Management and Penerbit Universiti Sains Malaysia, 2019. This work is licensed under the terms of the Creative Commons Attribution (CC BY) (http://creativecommons. org/licenses/by/4.0/). 


\section{INTRODUCTION}

Working in maritime industry is an exciting job and offers a good pay, but it exposes a dangerous working environment and high risk of accidents. Accidents lead to either a minor, major or sometimes fatal injury. Regardless of the positions, either working in a port as a longshoreman, aboard a ship as a seafarer, on an offshore platform, or in some other maritime roles, the work is often physically demanding, requires long hours, and exposes the workers to the risk of being involved in an accident. Maritime Injuries Center (MIC) identifies maritime injuries of the head, neck, and back as among the most common accidents in the maritime industry. Cargo handling at the port could cause workers to be struck on the head or body, which often result in a serious back or neck injury or a small bump on the head. The worst of these injuries results in lifelong health problems such as chronic pain or even paralysis. According to Hetherington, Flin and Mearns (2006), there are two areas of accident which are common, namely the influence of human errors and the interventions to ensure the shipping activities are safe. The study of seafarers' profession is usually conducted across the following areas: fatigue, stress, health, situation awareness, and teamwork, decision-making, communication, automation, and safety culture. This shows the relative contribution of individual and organisational factors in the shipping accidents by monitoring and modifying the human factors that contribute to the performance in maritime safety. Meanwhile, Hamid, Majid and Singh (2008) define an accident as an event which is out of any planning, desirable, expectation, or control. In addition, Gambatese, Hinze and Haas (1997) state that people would normally pay more attention to the accident that results in injuries. This is also agreed by Sharma, Yadav and Dorothy (2013), who state that $80 \%$ of the maritime accidents are due to human error from a small fire that leads to a big explosion. Moreover, Green and Senders (2004) state that humans commit errors because they have three fallible mental functions such as perception, attention, and memory which limit the ability to process information. The maritime accidents could be minimised by taking precautionary steps to effectively overcome any unwanted event at the workstation. In short, the human error factors which contribute to maritime accidents are essential to be examined. This research aims to achieve these objectives: (1) to examine the significant factors on human errors that contribute to the rate of maritime accident; and (2) to analyse the relationship between the significant factors with the rate of maritime accidents. This research is conducted in an oil and gas company and a government agency which are located in Lumut, Perak, Malaysia. The oil and gas company operates as a residential contractor for fabrication that engages in oil and gas fabrication, piping process and pipeline construction, plant maintenance, manpower supply, and project management. Meanwhile, the government agency chosen is a government department under the Ministry of Transport, Malaysia. 
This department involves in administering shipping and ports within Malaysian waters. The functions of this government agency are to ensure safe navigations of merchant vessels, provide services to merchant vessels such as ship inspection, certification, and registration and licensing, provide services to ships to navigate in Malaysian waters and ports, and supervise examinations of seafarers.

\section{LITERATURE REVIEW}

\section{Human Error}

Human error is defined as a result or effect of human actions, the causal factor of an accident, deliberate violation, and the actual action taken by a human being as mentioned by Hansen (2007). In general, researchers rarely agree on either a specific definition or how to prevent human error. The concept of human error is examined as currently used in the literature of a variety of industries and professions. As for this research, the definition of human error is absolutely focused on the maritime industry. According to Hansen (2007), any action done by a person unintentionally refers to human error. In addition, Toffoli et al. (2005) state that once this error has occurred, it started from bad to worse and led to a major accident. Therefore, it is crucial to eliminate the human error which could assist to reduce the number of marine accidents. The various definitions of human errors have been adopted by several researchers as shown in Table 1.

There are three factors that contribute to human errors, namely fatigue, communication, and lack of technical knowledge. They are reviewed in the following sections.

\section{Fatigue}

According to Sharma et al. (2013), fatigue is cited as the most common factor for mariners in different surveys and studies. In a study of critical vessel casualties and personal injuries, it was found that fatigue contributed to $16 \%$ of vessel casualties and $33 \%$ of injuries. Fatigue may occur due to poor health and lack of performance. Meanwhile, Hanzu-Pazara et al. (2008) claim that fatigue is the root cause of the human error. In addition, Oluseye and Ogunseye (2016) agree that fatigue contributes to the maritime accident as human error and leads to the high frequency of maritime accidents. It is employers' duty to manage the risks from fatigue, regardless of any individual's willingness to work extra hours or preference for certain shift patterns for social reasons. Compliance with the working time regulation is insufficient to manage the risks of fatigue. 
Ismila Che Ishak et al.

Table 1

Definitions of human error

\begin{tabular}{ll}
\hline Authors (year) & Definition \\
\hline Hansen (2007) & $\begin{array}{l}\text { Human error or negligence is defined as some actions that were } \\
\text { unintentionally done by the person; something that is inevitable or a } \\
\text { norm of human being that results in a malfunction or system error. } \\
\text { Precisely, it is away from a direct intention, desire or expectation. }\end{array}$ \\
The errors include neglected maintenance, tiredness, poor handling \\
of manoeuvres, lack of communication between crew members, an \\
inadequate response to a minor incident, or insufficient checking of \\
system causing it from bad to worse and leads to a major accident. \\
Considers human error, especially in the management of human- \\
machine interactions as inappropriate performance or behaviour, \\
depending on the context and dynamic contingencies and embedded \\
in a specific socio-technical environment. \\
Defines as an accident as a short, sudden, and unpredictable event \\
or occurrence that floats in an unsolicited and undesirable outcome, \\
refers to either an event, the result of an event, or the possible cause. \\
The failure to perform a task or the performance of a forbidden \\
action that could lead to the disruption of scheduled operations or \\
damage to a property and equipment.
\end{tabular}

Employees should be consulted on working hours and shift patterns. The employees may prefer certain shift patterns that are unhealthy and likely to cause fatigue. The employer needs to develop a policy that specifically addresses and sets limits on working hours, overtime and shift-swapping, which guards against fatigue. The implementation, arrangement, and monitoring of the regulated policy need to be enforced accordingly. This may also include developing a robust system of recording working hours, overtime, shift-swapping, and on-call working. Problems with overtime and shift-swapping are high due to inadequate resource allocation and staffing levels.

Different shift work schedules may create different schedule features. This sheer diversity of work and workplaces means that, there is no single optimal shift system that suits everyone. However, a strategic and systematic approach to assess and manage the risks of shift work can improve the workers' health and safety. In managing the risk of different shift work, the management needs to consider the number of key risk factors in the shift schedule design which include workload, work activity, shift timing, duration, the direction of rotation, number, and length of breaks during and between the shifts. In addition, the features of the workplace environment need to be managed properly which include physical environment, 
management issues, employee welfare, and sleep disturbances which could lead to fatigue. Most night workers are exposed to the risk of fatigue due to a lesser and shorter day sleep, and they are easily disturbed by the daytime noise and a natural reluctance to sleep during daylight as a collective state by Cacciabue (2013), Dekker (2017), Sharma et al. (2013), and Oluseye and Ogunseye (2016).

\section{Communication}

Hanzu-Pazara et al. (2008) state that poor communication exists due to language barriers, unfamiliar terminology, background noise, or failure to speak distinctly which leads to misunderstanding, mistakes, and ultimately, accidents. A person in charge must establish and maintain good communication to coordinate the efforts of a team. Good communication is vital between shipmates, masters, and pilots, ship-to-ship, and ship to Vessel Traffic Service (VTS). Better procedures and training can be designed to promote better communication and coordination on-board and between vessels. In addition, Sharma et al. (2013) conclude that inadequate communication triggers accidents during duty on the working site. Additionally, Oluseye and Ogunseye (2016) highlight that poor communication at the worksite is one of the human errors which cannot be avoided and will trigger marine accidents. Apostol-Mates and Barbu (2016) discover that the causes of the accidents are based on the type of breakdowns in four types such as: (1) problems related to multicultural crews, such as Bunga Teratai Satu accident, the Sally Maersk death, and the Scandinavian Star accident; (2) problems related to communication failure due to different cultural background between the crews and the pilot, such as the Bright Field accident; (3) problems related to miscommunication among crew members and passengers on passenger's vessels such as the Skagerak accident, and the Scandinavian Star accident; and (4) problems related to the usage of different languages with respect to external communication, and VHF communication with other vessels, such as the Royal Majesty accident.

\section{Inadequate general technical knowledge}

According to Hanzu-Pazara et al. (2008), inadequate general technical knowledge is responsible for $35 \%$ of casualties. The main contributor of this category is lack of technical knowledge of the proper use of technology due to limited training and development. Mariners often do not understand how the automation works or under what set of operating conditions it was designed to work effectively, such as radar. The unfortunate result is that, mariners sometimes make an error in using the equipment or depend on a piece of equipment as compared to getting any information from the other alternative sources. 


\section{DISTRIBUTION OF HUMAN ERROR CAUSE}

\section{Human Error Cause Distribution}

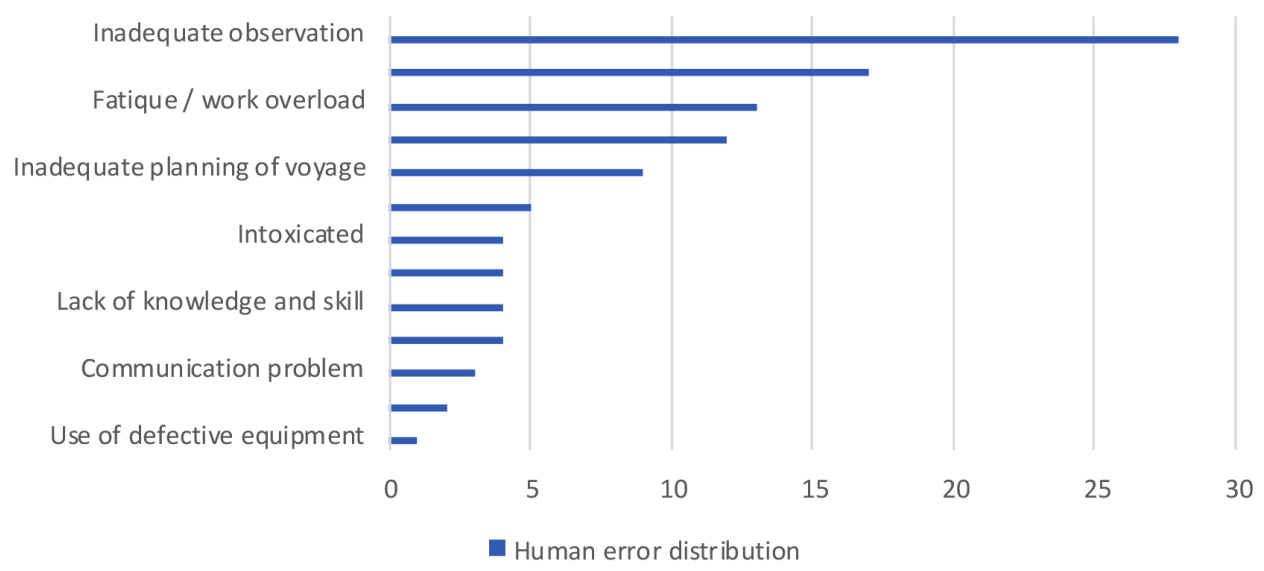

Figure 1. Human error cause distribution (source: STCW, 2011)

The rate of accidents relates to an occurrence of accidents in the workplace and it refers to the ratio of the number of accidents and workers. It is an indicator of health and safety conditions at work. It provides an outline for measuring the extent to which workers are protected from hazards associated with work at their workplace. The rate of accidents is the occurrence of an accident in an unplanned event and occurs as a combination of causes that result in a physical disturbance to the individual, damage to property, life or a combination of such effects. The variations in the risk of accident incidents occurring in different industries or such occupations and groups can be measured by taking the number of accidents as proportionate to the number of employees in each branch. The ratio obtained can be considered a risk figure in a job or industry. In practice, the accidental error is also different for a similar job or industry of a different task. The accidental rate data are used by governments, organisations, and other stakeholders to formulate policies and programs for the prevention and reduction of injuries, illnesses, and occupational deaths. It is also used to monitor the extent of compliance and how the program is implemented in a specific industry, place of employment, or location. It is crucial for smaller organisations which consist of smaller number of employees but produce a high rate of accidents (Hamid, Majid \& Singh, 2008). 


\section{THEORETICAL FRAMEWORK}

Based on the literature review, the following theoretical framework has been developed to determine the relationship between the independent and dependent variables. The basic proposition of this framework is that, any human errors could lead to maritime accidents. However, the independent variables for this research are limited to the most common human error factors that lead to a high number of accidents which are fatigue, communication, and lack of technical knowledge, as identified in the literature previously discussed. The dependent variable is the rate of maritime accidents.

Independent variables

Dependent variable

Human error factors:

1) Fatigue

2) Communication

3) Lack of technical knowledge

\section{Rate of maritime accidents}

Figure 2. Research framework

\section{HYPOTHESIS}

Hypothesis test of the significance of the correlation coefficient is used to decide whether the linear relationship in the sample data is strong enough to use in order to model the relationship in the population. In this research, this hypothesis test will decide whether the value of the population correlation coefficient, $\rho$ is close to zero or significantly different from zero. The decision is based on the sample correlation coefficient, $r$, and the sample size $n$.

\section{Null hypothesis $\mathrm{H}_{0}: \mathrm{H}_{0}: \rho=0$}

The population correlation coefficient for fatigue, communication, and lack of technical knowledge is not significantly different from zero.

\section{Alternate hypothesis $\mathrm{H}_{\mathrm{A}}: \mathrm{H}_{\mathrm{A}}: \rho \neq 0$ or $\mathrm{H}_{\mathrm{A}}: \rho<0$ or $\mathrm{H}_{\mathrm{A}}: \rho>0$}

The population correlation coefficient for fatigue, communication, and lack of technical knowledge is significantly different from zero. 


\section{RESEARCH METHODOLOGY}

A survey method is applied to collect relevant data from targeted respondents in line with the objectives of the research. This research tries to hypothesise, verify, and establish the relationship between fatigue, communication, and lack of technical knowledge with maritime accident rate in the maritime-related organisations. The unit of analysis in this research is individual from the maritimerelated organisations.

\section{Populations, Samples, and Respondents}

The samples for the current study consist of 200 employees in an oil and gas company and a government agency in Lumut, Perak, Malaysia. The samples were drawn using Airasian and Gay (2003), who suggested that, for descriptive research, the samples should be between $10 \%$ to $20 \%$ of the total population. Therefore, following Airasian and Gay (2003), 90 questionnaires were sent, and 60 responses were received, so the overall response rate was $66.67 \%$, collected from these two maritime organisations. The breakdown is shown in Table 2. The oil and gas company and the government agency were selected due to their location in Lumut, Perak and their involvement in the maritime operations which are exposed to maritime accidents. The profile of the respondents is shown in Table 3.

\section{Instruments}

The instrument of the study is divided into four parts. The first part of the questionnaire is regarding the respondents' background which represents gender, race, marital status, level of education, and working experiences. The second part covers the background of the company. The third part inquires the measurement of human error of fatigue, communication, and lack of technical knowledge with a Likert scale of 1-5, which indicates 1 (Strongly Disagree), 2 (Disagree), 3 (Neutral), 4 (Agree) and 5 (Strongly Agree) . It was developed by Likert (1932) to measure attitudes. The typical Likert scale is a 5- or 7-point ordinal scale used by the respondents to rate the degree to which they agree or disagree with a statement as mentioned by Sullivan and Artino (2013). The fourth part of the questionnaire covers the rate of maritime accidents by $1-5$ Likert scale. To measure the human error, there are 28 items included in the questionnaire, of which 7 items are used to measure each of the variables namely fatigue, communication, lack of knowledge, and maritime rate of accidents. The items in the questionnaire are adopted and adapted from several references on human error studies and some are self-constructed. Therefore, face and content validity are conducted on all 
the measurements. The scale items are screened by two subject matter experts from the field of maritime management and two practitioners in the maritime management area. The comments and suggestions are considered in improving the questionnaire. A pilot test is conducted among the industrial-experienced staff of the maritime institutions and an oil and gas company in Kuala Lumpur.

Table 2

Population, sample and respondents

\begin{tabular}{lccc}
\hline List of population & Population & Sample & Respondents \\
\hline Oil and gas company & 150 & 60 & 40 \\
Government agency & 50 & 30 & 20 \\
Total & 200 & 90 & 60 \\
\hline
\end{tabular}

Table 3

Respondents' profile

\begin{tabular}{lcc}
\hline Parameter & Frequency & Percentage \\
\hline Gender & 52 & \\
Male & 8 & 86.7 \\
Female & & 13.3 \\
Race & 48 & \\
Malay & 4 & 80.0 \\
Chinese & 8 & 6.7 \\
Indian & & 13.3 \\
Marital status & 22 & \\
Single & 38 & 36.7 \\
Married & & 63.3 \\
Level of education & 14 & \\
SPM & 24 & 23.3 \\
Diploma & 22 & 30.0 \\
Degree & & 36.7 \\
Working experience & 26 & 43.3 \\
1-5 years & 19 & 31.7 \\
6-10 years & 9 & 15.0 \\
11-15 years & 6 & \\
16-20 years & & \\
\hline
\end{tabular}




\section{DATA ANALYSIS AND RESULTS}

\section{Correlation}

The correlation analysis is used to obtain the degree and direction and gives an estimated relationship between the two variables as stated by Puth, Neuhäuser and Ruxton (2014). As for the range of correlation coefficient ( $r$ ), the value of $r=0.80$ is considered high and it is acceptable to mention the positive and strong relationship between the variables. This is supported by Cortina (1993), who shows that the closer the correlation to 1.0, the stronger the relationship between the two variables is. In this case, it means that high scores on one are associated with high scores on the other and that low scores on one are associated with low scores on the other. The higher score on the factors of failure in the marine company will produce a higher rate of accidents. The Pearson correlation coefficient requires both variables to be measured on an interval or ratio scale, and calculations based on actual values. A close relationship with +1 has a strong relationship while the correlation with 0 or -1 has a correlation between variables but with a coefficient of the correlation coefficient.

Table 4 shows the correlation between fatigue and accident rate which is positively correlated and can be proved by the high value of 0.722 . This positive relationship means that the relationship between fatigue and accident rate is strongly correlated. This correlation value is the second highest.

Table 4

Correlation between fatigue and rate of maritime accidents

\begin{tabular}{llcc}
\hline & & Fatigue & Rate of accidents \\
\hline Fatigue & Pearson correlation & 1 & $\mathbf{0 . 7 2 2}^{\text {** }}$ \\
& Sig. (2-tailed) & & 0.000 \\
& $\mathrm{~N}$ & 60 & 60 \\
Rate of accidents & Pearson correlation & $\mathbf{0 . 7 2 2}^{\text {** }}$ & 1 \\
& Sig. (2-tailed) & 0.000 & 60 \\
\hline
\end{tabular}

**Correlation is significant at the 0.01 level (2-tailed)

Table 5 indicates that communication and accident rates are also strongly correlated at 0.693 . The relationship value is less than the relationship between fatigue and accident rate. This correlation value is the third highest. 
Table 5

Correlation between communication and rate of maritime accidents

\begin{tabular}{llcc}
\hline & & Communication & Rate of accidents \\
\hline Communication & Pearson correlation & 1 & $\mathbf{0 . 6 9 3}^{\text {** }}$ \\
& Sig. (2-tailed) & & 0.000 \\
& $\mathrm{~N}$ & 60 & 60 \\
Rate of accidents & Pearson correlation & $\mathbf{0 . 6 9 3}^{* *}$ & 1 \\
& Sig. (2-tailed) & 0.000 & 60 \\
& $\mathrm{~N}$ & 60 & \\
\hline
\end{tabular}

**Correlation is significant at the 0.01 level (2-tailed)

The correlation between lack of knowledge and the accident rate shows a positive correlation as shown in Table 6. This is evidenced by the highest correlation value of 0.782 as compared with the correlation of the other two human factors. Lack of technical knowledge is highly associated with accidents in the maritime industry. The correlation between the two elements is stronger because the correlation value is at 0.8 and shows the strongest relationship.

Table 6

Correlation between lack of knowledge and rate of maritime accidents

\begin{tabular}{llcc}
\hline & & Lack of knowledge & Rate of accidents \\
\hline Lack of knowledge & Pearson correlation & 1 & $\mathbf{0 . 7 8 2}^{\text {** }}$ \\
& Sig. (2-tailed) & & 0.000 \\
& $\mathrm{~N}$ & 60 & 60 \\
Rate of accidents & Pearson correlation & $\mathbf{0 . 7 8 2}^{* *}$ & 1 \\
& Sig. (2-tailed) & 0.000 & 60 \\
\hline
\end{tabular}

***Correlation is significant at the 0.01 level (2-tailed)

Table 7 explains a coefficient output of collinearity statistics obtained by the Variance Inflation Factor (VIF). The value between 1.63 and 2.541 indicates that there is no multicollinearity symptom. This test is to determine whether there is similarity between the independent variables in a model. Similarity between the independent variables will result in a very strong correlation. A VIF greater than 5 is generally considered evidence of multicollinearity. 
Ismila Che Ishak et al.

Table 7

Correlation of variables

\begin{tabular}{lcc}
\hline \multirow{2}{*}{ Model } & \multicolumn{2}{c}{ Collinearity statistics } \\
\cline { 2 - 3 } & Tolerance & VIF \\
\hline Fatigue & 0.417 & 2.125 \\
Communication & 0.614 & 1.63 \\
Lack of knowledge & 0.394 & 2.541 \\
\hline
\end{tabular}

\section{Multiple Regression Analysis}

Table 8

\section{Correlation result}

\begin{tabular}{ccccc}
\hline Model & $\mathrm{R}$ & $\mathrm{R}^{2}$ & Adjusted $\mathrm{R}^{2}$ & Std. error of the estimation \\
\hline 1 & -850 & 0.723 & 0.708 & 0.18369 \\
\hline
\end{tabular}

Predictors: (constant), lack of knowledge, communication, fatigue

Table 9

ANOVA Test

\begin{tabular}{lccccc}
\hline Model & Sum of squares & df & Mean square & F & Sig. \\
\hline Regression & 4.935 & 3 & 1.645 & 48.752 & 0.000 \\
Residual & 1.890 & 56 & & & \\
Total & 6.824 & 59 & & & \\
\hline
\end{tabular}

Dependent variable: Rate of accidents; Predictors: (constant), lack of knowledge, communication, fatigue

Table 10

Regression coefficients model

\begin{tabular}{|c|c|c|c|c|c|c|c|}
\hline \multirow{2}{*}{ Model } & \multicolumn{2}{|c|}{$\begin{array}{c}\text { Unstandardised } \\
\text { coefficients }\end{array}$} & \multirow{2}{*}{$\frac{\begin{array}{c}\text { Standardised } \\
\text { coefficients }\end{array}}{\beta}$} & \multirow{2}{*}{$t$} & \multirow{2}{*}{ Sig. } & \multicolumn{2}{|c|}{$\begin{array}{c}95.0 \% \text { confidence } \\
\text { interval for B }\end{array}$} \\
\hline & B & Std. error & & & & $\begin{array}{l}\text { Lower } \\
\text { bound }\end{array}$ & $\begin{array}{l}\text { Upper } \\
\text { bound }\end{array}$ \\
\hline (Constant) & 0.653 & 0.305 & & 2.142 & 0.037 & 0.042 & 1.264 \\
\hline Fatigue & 0.283 & 0.101 & 0.288 & 2.809 & 0.007 & 0.081 & 0.485 \\
\hline Communication & 0.277 & 0.080 & 0.313 & 3.489 & 0.001 & 0.118 & 0.437 \\
\hline Lack of knowledge & 0.307 & 0.090 & 0.381 & 3.399 & 0.001 & 0.126 & 0.487 \\
\hline
\end{tabular}

Dependent variable: Rate of accidents 
Correlation and multiple regression analysis were conducted to examine the relationship between the rate of accidents and the potential predictors. The regression coefficients show the changes in the dependent variable when independent variables change. Table 8 shows a value of 0.850 which indicates a good level of prediction. The coefficient of determination $\left(\mathrm{R}^{2}\right)$ states the value of 0.723 , which means that the independent variables explain $72.3 \%$ of the variability of the dependent variable. Thus, it can be claimed that the model explains a significant amount of the variance in the rate of accident. Table 9 shows the result of ANOVA, i.e., whether the overall regression model is a good fit for the data. It shows that the independent variables statistically and significantly predict the dependent variables $F(3,56)=48.752, p<0.005$. The regression model is a good fit for the data. Table 10 shows the result of the regression model. The unstandardised coefficient $\mathrm{B}$ for fatigue, communication, and lack of knowledge are $0.283,0.277$, and 0.307 , respectively. It indicates that fatigue, communication, and lack of knowledge increase in the rate of the accident at $0.283 \%, 0.277 \%$, and $0.307 \%$. The result impacts the value of the dependent variable. The multiple regression is analysed to predict the rate of accidents which are caused by fatigue, communication, and lack of knowledge. These variables statistically and significantly predicted the rate of the accident with the $F(3,56)=48.752, p<0.005, \mathrm{R}^{2}=0.723$. All these three variables statistically significant in explaining accident rates at the $5 \%$ level.

\section{HYPOTHESIS TESTING}

Hypothesis testing for the three independent variables which include fatigue, communication, and lack of technical knowledge reveals a value of coefficient correlation $r$ of $0.722,0.693$, and 0.782 , respectively. This test uses the number of sample $n=60$, the degree of freedom $\mathrm{df}=n-2=60-2=58$, and critical values table for $r$ with $\alpha=0.05$. The sample correlation coefficient table calculated the critical values of fatigue, communication, and lack of technical knowledge are \pm 0.260 . Since the value of $0.722>0.260,0.693>0.260$ and $0.782>0.260$ for fatigue, communication, and lack of technical knowledge show that $r$ is significant. Therefore, the null hypothesis is rejected and this shows enough evidence to conclude that there is a significant linear relationship between fatigue, communication, and lack of technical knowledge. 


\section{CONCLUSION}

This study found that human error of fatigue, communication, and lack of technical knowledge had a significant impact on the rates of maritime accident. The lack of technical knowledge is the most significant factor compared with fatigue and communication variables. This study has successfully expanded the research conducted by Oluseye and Ogunseye (2016), Apostol-Mates and Barbu (2016), Sharma et al. (2013), and Hanzu-Pazara et al. (2008), based on the theory of human error in the maritime accidents. The human ability to determine important inputs in choosing the right action is important so that it assists to reduce the accidents not only in the maritime industry but also in all other working environments. The human error is a term which is often used and emphasised by many researchers. Through the facing slip inclusion, errors, violations, and errors in the definition of past mistakes illustrate an interesting picture of the dynamics of human involvement towards the accidents. The human error and human limitations play an important role in maritime accidents which cannot be regarded as a common phenomenon. Developing a narrow definition of human error allows future researchers to develop a specific strategy to minimise the impact of true human error in accidents.

\section{RECOMMENDATION}

Human errors contribute more than $80 \%$ failure and disability in the workplace. The human condition cannot be changed, but a condition where the human is working can be changed and upgraded. It is suggested that the systems and operation control need to be reviewed and evaluated regularly and the content should cover management system, procedure, human factor engineering, exercise, immediate supervision, communication, and individual performance. It is recommended to establish a basis for all operations in the management system which refers to the documentation control, investigation management, risk management, and project management. Meanwhile, a precise procedure on a requirement of the accuracy, humanised, resources available, and enforcement of law need to be updated. Furthermore, a regular exercise or training should be included which could help in reducing the rate of maritime accidents. It is beneficial to conduct a proper and efficient on the job training (OJT) which is a necessary enforcement especially for critical tasks and activities. On top of that, immediate supervision is compulsory and mandatory for visits, attendance, and instructions to related employees which require proper supervision at the floor and at the office. Besides that, effective communication requires employees to know what to achieve in their everyday work and the right system to perform through communication between groups, transitions, radio communication, and training regulations. Finally, there is a need 
to assess the individual performance based on the potential conditions which may lead to triggering an attention and memory failure among human. This includes availability of time for work, fitness for a task, tight management schedule, task design, and task complexity.

\section{ACKNOWLEDGEMENTS}

This research paper is conducted with the collaboration from an oil and gas company and a government agency located in Lumut, Perak, Malaysia. This research is financially supported by Universiti Kuala Lumpur Malaysian Institute of Marine Engineering Technology (UniKL MIMET). Certainly, without the cooperation granted from all dedicated team members and, the respective respondents this research cannot be successfully implemented and completed.

\section{REFERENCES}

Airasian, P.W., \& Gay, L.R. (2003). Educational research: Competencies for analysis and application. London: Prentice Hall.

Apostol-Mates, R., \& Barbu, A. (2016). The human error-the main factor in marine accidents. Naval Academy Scientific Bulletin, 19(2), 451-454.

Cacciabue, P.C. (2013). Guide to applying human factors methods: Human error and accident management in safety-critical systems. London: Springer Science \& Business Media.

Cortina, J.M. (1993). What is coefficient alpha? An examination of theory and applications. Journal of Applied Psychology, 78(1), 98. https://doi.org/10.1037//00219010.78.1.98

Dekker, S. (2017). The field guide to understanding “human error." New York: CRC Press. https://doi.org/10.1201/9781315239675

Dhillon, B.S., \& Liu, Y. (2006). Human error in maintenance: A review. Journal of Quality in Maintenance Engineering, 12(1), 21-36. https://doi. org/10.1108/13552510610654510

Gambatese, J.A., Hinze, J.W., \& Haas, C.T. (1997). A tool to design for construction worker safety. Journal of Architectural Engineering, 3(1), 32-41. https://doi. org/10.1061/(ASCE)1076-0431(1997)3:1(32)

Green, M., \& Senders, J. (2004). Human error in road accidents. Visual Expert. Retrieved 20 January 2017 from https://www.visualexpert.com/Resources/roadaccidents. html.

Hansen, F.D. (2007). Human error: A concept analysis. Journal of Air Transportation, $11(3), 61-77$. 
Hanzu-Pazara, R., Barsan, E., Arsenie, P., Chiotoroiu, L., \& Raicu, G. (2008). Reducing maritime accidents caused by human factors using simulators in the training process. Journal of Maritime Research, 5(1), 3-18.

Hamid, A.R.A., Majid, M.Z.A., \& Singh, B. (2008). Causes of accidents at construction sites. Malaysian Journal of Civil Engineering, 20(2).

Hetherington, C., Flin, R., \& Mearns, K. (2006). Safety in shipping: The human element. Journal of Safety Research, 37(4), 401-411. https://doi.org/10.1016/j. jsr.2006.04.007

Hollnagel, E., \& Goteman, O. (2004). The functional resonance accident model. Proceedings of Cognitive System Engineering in a Process Plant, 155-161.

Likert, R. (1932). A technique for the measurement of attitudes. Archives of Psychology.

Oluseye, O.O., \& Ogunseye, O.O. (2016). Human factors as determinants of marine accidents in maritime companies in Nigeria. Journal of Maritime Research, 13(3). https://doi.org/10.9734/BJESBS/2016/29548

Puth, M.T., Neuhäuser, M., \& Ruxton, G.D. (2014). Effective use of Pearson's productmoment correlation coefficient. Animal Behaviour, 93, 183-189. https://doi. org/10.1016/j.anbehav.2014.05.003

Sharma, S.B., Yadav, R., \& Dorothy, B.C. (2013). A study on human errors and classification of commonly prevalent errors in shipping operational practices. AMET International Journal of Management, July-December, 1-7.

STCW. (2011). International Convention on Standards of Training, Certification and Watchkeeping for Seafarers (STCW) 1978, as amended in 1995/2010. International Maritime Organisation, London.

Sullivan, G.M., \& Artino Jr., A.R. (2013). Analyzing and interpreting data from Likert-type scales. Journal of Graduate Medical Education, 5(4), 541-542. https://doi.org/10.4300/JGME-5-4-18

Toffoli, A., Lefevre, J.M., Bitner-Gregersen, E., \& Monbaliu, J. (2005). Towards the identification of warning criteria: Analysis of a ship accident database. Applied Ocean Research, 27(6), 281-291. 